\title{
MESTRE EM TEMPO DO CONTRA (1)
}

\author{
(para Antonio Candido) \\ Ligia Chiappini Morais Leite
}

\begin{abstract}
"A admiração, o respeito pelo mestre, quando se tem a sorte de ter conhecido um, tingem-se duma leve melancolia a partir da altura em que se aprende que a mais alta capacidade só pode ser adquirida por ertre a dúvida".
\end{abstract}

(Georges Gusdorf, Professores para quê??)

"Adote um artista antes que ele se torne professor"

Eis aí um slogan publicitário corrente na televisão de São Paulo/77, que sintetizava para as "massas" a história de uma degradação.

Como nos conta brevemente Daniel Hameline, o desprestígio do professor em nossa era, de um capitalismo avançado, é coisa que vem crescendo já há algum tempo, em contraste com o extremo respeito que lhe era atribuído no século passado:

"Nessa época (fim do século XIX), a confiança na instrução é geral. É ela que liberará os espíritos da ignorância e das supertiçōes,

(1) - O processo de composição deste texto tem muito de bricolagem. Feito, na maior parte, de citações de algumas leituras fundamentais (de o.igem francesa, sobretudo) sobre a função do professor, não deve entretanto ser visto como simples justaposição de textos, porque faço questão de sustentar a sua coerência de fundo. Sei de onde parto e para onde me dirijo. Se, no caminho, encontro quem exprima o que eu gostaria de dizer, cito. E, assim aproveito para incitar à leitura dos textos que me serviram. Chamo atenção ainda, para a perspectiva atual com que o escrevo. Isto é, por trás da bibliografia francesa, e sob o aparente tom genérico, está o caso brasileiro, a universidade brasileira (diria mesmo paulista) de hoje, em questão. Não é por acaso, por exemplo, que o título é extraido da intervenção de Antonio Cândido num debate da ADUSP("A cultura do contra" Folha de São Paulo julho/78)

Este trabalho foi redigido durante a vigência de uma bolsa de pós-doutora. mento, concedida pela FAPESP para o desenvolvimento de uma pe quisa scbre o ensino da literatura. 
que assegurará a igualdade entre os cidadãos e c triunfo de uma nova sociedade, republicana, leiga e traternal. $\mathrm{Na}$ aurora de uma civilização científica, técnica, industrial, a escola aparece para todos como o próprio motor do progresso, da justiça e da felicidade. Cabe a ela inculcar, no respeito e na tolerância, os novos preceitos de uma moral leiga, enfim livre do obscurantismo e das influências dos padres (.. ). Entretanto, desde antes das grandes agitaçōes da Segunda Guerra Mundial, da expansão industrial gałopante (195u-197v), alguns dão sinal de alarme: o que os professores fabricam, na realidade, não corresponde à idéia que eles têm e à maneira de falar dos discursos pedagógicos. Há um grande fosso entre o que os professores creêm fazer e o que efetivamente o sistema escolar os conduz a fazer." (2)

E ainda o mesmo autor que tenta precisar em que sentido se dá esse mesmo desprestígio:

"A mudança cultural que se desenrola neste momento, no conjunto das nações civilizadas, põe em causa a função docente na sua definição mesma: não é o autoritarismo de tal ou qual professor que é criticado, mas antes a utilidade mesma do ato de ensinar em geral." (3) .

Diante da desorientação geral, há os que meīancolicamente lamentam os calmos tempos em que, ao abrigo das igrejas, os grandes mestres universitários resguardavam das multidões sua ciência, suas crenças e o seu prestígio. E o caso de Georges Gusdorf, quando nos diz que "os mestres" de hoje não sabem para onde vão, quanto menos para onde conduzir seus discípulos" A sua explicação para o fato é idealista: tudo se deve a uma "crise de consciência"; tendo-se perdido sucessivamente o ideal pedagógico da Paidéia grega, da Universidade Medieval e das Humanidades renascentistas (que definiam o "programa do homem de bem"), não se conseguiu ainda encontrar outro para substituí-los. Ilusório pensar que o iremos encontrar na ciência e na técnica, porque "o humanismo técnico não existe" O que existe é "ausência de um programa educativo susceptível de reunir a humanidade, de reconciliar o homem com o mundo e consigo próprio"

Gusdorf chega mesmo a perceber que "A pedagogia por si mesma não faz milagres", que "a elaboração de uma pedagogia supõe de algum modo o problema resolvido", mas na falta de uma perspectiva

(2) - Maitres et éleves, Paris. Hachette, 1973, pp. 8-9

(3) - Idem, ibidem, p. 76.

(4) - Professores para quê. 2a. ed, Lisboa, Moraes s.d. (1a ed. francesa, Payot, 1963, p. 301-2. 
totalizadora que lhe permita perceber as intimas conexões entre a fragmentação do que ele chama "ideal pedagógico" e as contradições sociais e econômicas da sociedade, só pode propor soluções miraculosas: "algum gênio que arrancasse o mundo de hoje à fascinação e sortilégio da civilização mecânica." (5)

Mas, nos mesmos anos 60, enquanto Gusdorf buscava o seu gênio salvador, outros investigadores-professores (entre os quais Bourdieu e Passeron, cujo livro Les Héritiers saiu em 1964) buscavam explicações mais globais para o fenômeno da crise educacional moderna. (6)

E mais uma vez, Daniel Hameline que resume os fatos:

"Os anos 60 verão a hora das tomadas de consciência coletivas. a hora também de novas tentativas para romper o encadeamento fatal do ato de ensinar a um sistema escolar cada vez mais inadapta. do face à origem das sociedades modernas. (...) quando se perceberá que a idéia muito bela, herdada dos fundadores da Escola Republicana mascara com efeito a dependência, em relação aos imperelativos sócio-econômicos de um sistema de ensino muito menos igualitário, justo e libertador do que se queria acreditar" (7)

Nessa mesma linha estão os textos de Georges Snyders, que culminam no livro de 1973 (Où vont les pédagogies non-directives?) Assim, por exemplo, se Gusdorf frcqüentemente descreve com pertinência os fenômenos (mostrando como "a função docente dissociou-se em especialidades cada vez mais estreitas; o especialista acantonou-se em seu canto; isolado dos vizinhos, encarregado de transmitir um saber fraccionado ( ) incapaz de compreender a significação e o valor do que ele faz") (8), não vai além da constatação empírica, enquanto Snyders busca, para o mesmo fenômeno, explicação que se apóia numa teoria da sociedade como um todo:

"É, antes de tudo pelo não-dizer que a escola serve o regime estabelecido ( .). É a recusa da cultura que permite à burguesia assentar sua exploração e não a extensão da cultura ( ). É precisamente para não falar do essencial que se desvia a aten-

(5) - Idem, p. 302.

(6) - Ed. de Minuit. Além desse livro de Bourdieu e Passeron, surge o artigo de Christian Baudelot, "La Rhétorique des étudiants è l'éxamen" in Rapport Pedagogique et Communication, Mouton, 1965. Já na década de 70, cita-se tambem o livro de Christian Baudelot L'école capitaliste en France, Maspero 1971, e, para o Brasil, um livro imprescindível. Manfredo Berger, Educação e Dependência, Porto Alegre, Difel/URGS, $197 \dot{6}$.

(7) - Op. cit., p. 9.

(8) - Op. cit., p. 305. 
ção sobre uma "massa de conhecimento inúteis, supérfluos, sem vida". A escola só pode ser morna cortada dos in:eresses dos alunos." (9)

O que foi dito aqui vale para o ensino, em geral, mas especificamente para os dois primeiros graus. Entretanto, a Universidade também paga seu tributo à desvalorização do professor, considerando quase sempre o ensino como sua função menor, em relação a uma supervalorização do que chama (mas nem sempre é) investigação.

Vladimir Kourganoff, astrofísico francês, professor na Universidade de Paris-Sud, dedica um livro inteiro à tentativa de desvendar o que ele chama a "cara oculta da Universidade", que tem muito a ver com o esquecimento em que freqüientemente é deixada a questão do ensino nessa Instituição. Seu ponto de partida são perguntas como esta: "Não é chocante ver que a maioria dos docentes-investigadores consideram que uma de suas funções, a de investigador, é prestigiosa, importante, exaltante, enquanto a outra, a docente, é desprovida de todo interesse?" (10)

Polêmico, às vezes demasiado esquemático, Kourganoff não deixa de colocar o dedo em questões fundamentais, quase sempre obliteradas pelo discurso universitário. Embora sejam simples como a anterior, ou como esta outra: é do ensino que, em última instância, se vive na Universidade mas é exclusivamente pela pesquisa que se ascende na carreira.

Nessa defesa do ensino transpira, entretanto, um certo desprezo pela pesquisa. E a análise beira o maniqueísmo. Kourganoff acaba postulando uma discutível incompatilidade de base entre a investigação e o ensino como atividade de uma mesma pessoa. Vejo aí o perigo de esvaziar o professor de conteúdos próprios, transformando-o em simples repetidor de pesquisas alheias. (11)

$\mathrm{O}$ assunto (ruptura entre ensino e pesquisa) tem sido objeto de muitas discussões, especialmente depois de 1968, na França. E to-

(9) - Georges Snyder, Où vont les pédagogies non-directives?, Paris PUF., 1973, p. 304.

(10) - V Kourganoff, La Cara Oculta de la Universidad, Buenos Aires, Ed. Siglo Viente, 1972, p. 101.

(11) - Embora Kourganoff observe que ninguém consegue ser simplesmente um repetidor e, no trabalho de síntese e escolha, feito pelo professor, se exige um talento especial, prefiro não fazer tão drasticamente a distinção entre esse trabalho e a investigação, pois, até que ponto podemos negar como pesquisa, pelo menos no que toca às ciências humanas (e, especialmente, os estudos literários), um esforço de seleção e síntese, se ele realmente for sério e aprofundado? 
das elas acabam apontando para essa separação drástica entre o pesquisador e o professor, como sendo uma das principais causas da esclerose do ensino em todos os graus. (12)

Em letras, pelo menos, a experiência nos diz que a pesquisa é o alimento do professor, o que é mais ou menos um consenso. Mas, embora disto já não comparta a opinião geral, eu diria que a recíproca é também verdadeira: o ensino é o alimento do pesquisador.

Descontando, portanto, um certo dogmatismo de Kourganoff em relação à pequisa não podemos deixar de admitir o que, no seu livro, vai contra o mito da "investigação" quando esta conduz não a conquistas do conhecimento, mas à simples promoção pessoal dos "investigadores" e à carreira desenfreada, às publicações que engordam currículos.

"Publicar ou perecer" é de fato, o slogan que retumba na cabeça dos universitários, hoje, no mundo inteiro, onde se impõe cada vez mais o modelo americano de Universidade. O Brasil, com seu moderno sistema de pós-graduação e as sucessivas re-estruturações da carreira universitária, segue o mesmo caminho.

Mas se Kourganoff desvaloriza, de certo modo a pesquisa, para supervalorizar o ensino, encontramos a posição contrária, quase simetricamente oposta, num texto bastante diferente, cuja sutileza não consegue ocultar o menosprezo pelo professor universitário. Trata-se de texto de Maurice Blanchot, "O pensamento e a exigência de descontinuidade" (13), em que defende a descontinuidade como fator imprescindível ao livre e pleno desenvolvimento do pensamento filosófico. Descontininidade que é sistematicamente negada, segundo ele, pelo pensamento filosófico, quando este é produto da Instituição

(12) - Aludo especialmente aos trabalhos que se seguiram ao Co'óquio de Cérisy- La Salle (1969), sobre O Ensino da Literatura (Paris, Plon, 1972), como os do Colóquio de Strasbourg, de 1975 (Michel Mansuy, L'enseignement de la littérature, crise et perspectivas, Nathan), os estudos do grupo da revista Pratiques (Metz e da revista Littérature (especialmente os $n^{0} 7$ e 19); a discussão dos problemas re'ativos ao ensino da literatura e o relato de experiências de vários grupos franceses, em Poétique, 30, ou a livros isolados, como o de France Vernier L'Ecriture et les Txtes, Paris, Éditions Socinles, 1974. E deixo aqui os meus agradecimentos a um colega da Universidade Estadual de Campinas, atualmente em Paris, preparando um estudo sobre os manuais de literatura, porque comigo compartilhou os dados bibliográficos sobre o assunto, indicando e, muitas vezes emprestando, livros e revistas. Seu nome: José Dias (Fac. Educação/Unicamp)

(13) - Maurice Blanchot, L'entretien infini, Paris, Gallimard, 1969, p.

$$
11 .
$$


universitária, ou seja, quando o filósofo é também professor Porque a forma desse pensamento é a "exposé", "dissertação escolar e universitária"

Assim, segundo Blanchot, dos gregos aos tempos modernos, co-existem duas correntes de pensamento. A do fragmento (pontilhada pelos nomes de Heráclito, Platão, Pascal, Nietzsche, Bataille, René Char) e a da linguagem esférica, contínua: de Parmênides a Kant e Hegel. O tempo de Hegel seria o tempo alto desse pensamento contínuo, produto da Universidade.

Submeter-se a isso tem como consequiência direta uma filosofia que descarta o momento da descontinuidade e privilegia a síntese, o que formalmente se traduz pela "monotonia do desenvolvimento em três tempos" e "institucionalmente', pela identificação "da razão com o Estado" e da "sabedoria com a Universidade"

Já o pensamento descontínuo respeitaria a distância radical que define a relação mestre-discípulo, assim entendida:

"O mestre representa uma região absolutamente outra do espaço e do tempo; isto significa que há por sua presença, uma dissimetria nas relações de comunicação (...) o mestre não é, portanto, destinado a fazer desaparecer o campo das relações, mas a agitá-lo; não facilitar os caminhos do saber, mas em primeiro lugar a torná-los não somente mais difíceis, mas propriamente infranqueáveis, o que a tradição oriental da maestria mostra bem"

O pensamento contínuo da filosofia universitária achataria essa relação, reduzindo-a a uma relação simples e linear que no fundo, se constitui numa relação de poder: "o desconhecido se confunde com a pessoa do mestre e é então seu valor próprio, seu valor de exemplo, seus méritos de Guru e de Zaddik (sua transcedência de mestre), não mais a forma do espaço interrelacional de que ele é um dos termos, que se torna princípio de sabedoria"

O sábio, aceitando desaparecer na Instituição, achataria igualmente a Filosofia no discurso professoral: "a palavra que ensina não é em nada aquela que a estrutura mestre/discípulo nos revelou própria a se abrir sobre uma ruptura fundamental, mas ela se contenta com a tranqüila continuidade discursiva. ( ) o filósofo

$$
\begin{aligned}
& \text { (14) - Op. cit., p. 3'. } \\
& (15) \text { - Op. cit., p. 5. } \\
& (16)-\text { Op. cit., p. 5-6. }
\end{aligned}
$$


transformado em professor, determina um achatamento visível da Filosofia .

Embora ressalvando que não há intenção pejorativa de sua parte, em relação ao pensamento universitário, Blanchot se inclina decisivamente para o filósofo marginal à Universidade. Sua opção parece ser por uma espécie de filósofo puro, não contaminado pelo professor. Nietzsche é seu exemplo máximo. E não é sem certo pezar que reconhece: "E, entretanto, o filósofo não pode mais evitar de ser professor de filosofia" E, admitindo que Kirkegaard "engendra grandes universitários", lembra também que muitas das questões fundamentais e das obras máximas da História da Filosofia nasceram vinculadas a um trabalho de professor. (cita, por exemplo, o caso de Heidegger, cuja obra é em grande parte feita de cursos e trabalhos universitários)

Pela simples razão de que nos lembra fatos como esse (da história da Filosofia e da Universidade), Blanchot acaba por nos fornecer argumentos contra a separação exagerada entre o ensino e a pesquisa, tal com é feita por Kourganoff. Curiosamente, porque ao contrário das intenções do seu texto (que, no fundo só admite a verdadeira pesquisa fora da Universidade) ele, nos permite pensar que as duas atividades (ensino e pesquisa) não devem ser tão incompatíveis assim, se andam juntas há tanto tempo, exercidas por tantos pesquisadores e ilustres professores.

Mesmo porque sua tese do rebaixamento da Filosofia pelo discurso universitário é altamente discutível. É o que começamos a perceber quando observamos que, sob uma aparente objetividade, e sob um aparente anti-hegelianismo seu texto esconde uma ideologia idealista e "hegeliana" Toda a história da filosofia é aí vista de maneira línear e, na linha traçada, todas as peças se ajuntam, para desaguar em Hegel. O discurso universitário é visto de maneira monolítica, sem contradições possíveis. Em nenhum momento se aponta para a possibilidade de uma luta interna à Instituição. A filosofia aí produzida tem que necessariamente ajustar-se à visão de mundo dominante na Universidade. Por outro lado, há o desejo de resgatar a "pureza" da Filosofia, desejo que se apóia numa apologia do fragmento, visto como o verdadeiro achado da modernidade, que, por sua vez é vista, (aqui, como em outras obras de Blanchot), como o tempo ideal onde convergem todas as conquistas do pensamento. Se quiséssemos fazer caricatura, diríamos que, do fundo do texto de 
Blanchot, brota este grito paródico: "Adote um filósofo, antes que ele se torne professor"

Mas, afinal como garantir que o fato de ser produzida na Universidade condene a Filosofia, necessariamente a se identificar à Instituição e a identificar Razão e Estado? Quem pode afirmar que, dentro da Instituição, a única relação possível entre mestre e discípulo é a do Guru para o fanático? Não dependeria tudo, em grande parte, da visão da Instituição que se tenha, de quem a Instituição serve, a que se serve dentro, pela e até, apesar da Instituição? O mínimo que podemos pensar, à medida que conseguimos penetrar um pouco a trama bem tecida do ensaio de Blanchot, é que felizmente as coisas são bem mais contraditórias do que ele pensa .

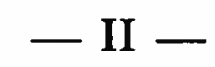

"A palavra do mestre é uma palavra mágica. Ao apelo de um espírito outro espírito desperta: pela graça de um encontro, uma vida foi mudada"

A citação acima, extraída do livro de Gusdorf, dá o tom geral desta segunda parte, porque, mesmo aceitando as críticas que lhe são feitas - sobre a maneira idealista de conceber a relação mestre-discípulo como " encontro de eleitos",

- sobre o conseqüente desprezo pelo aluno "médio" e pelo professor "médio" que seriam naturalmente menos dotados e, portanto, não alcançariam definir essa relação privilegiada,

- sobre a "imagem romântica (que fornece) do trabalho do intelectual como criação livre e inspirada" (18),

não podemos negar que consegue pôr o dedo em certas questões importantes que a Sociologia da Educação não esclarece, e das quais destaco as seguintes:

- é inegável que, na história de cada um de nós, há professores que nos marcaram mais que outros,

- é inegável que, se assim foi, é porque nos souberam conduzir, através do estudo de disciplinas específicas, a formulações (parciais, mas decisivas) de valores e princípios norteadores de um destino,

- é inegável que, "o ato pedagógico, em cada situação particular, ultrapassae em muito os limites dessa situação particular, para pôr em causa a existência pessoal no seu conjunto"

(18) - Ver Daniel Hameline. op. cit., pp. 16-17, "documentos"

(19) - Gusdorf, op. cit., p. 18. 
- e, razão mais subjetiva, mas nem por isso menos verdadeira, mestres há, porque eu conheço pelo menos um.

Assim, uma vez "demonstrado" que existem mestres, podemos tentar resgatar, com Gusdorf, o que resta de mágico ou de poético na figura desse herói degradado: o professor. (20)

Se podemos conceber o professor como um agente dos aparelhos ideológicos do Estado (Althusser), podemos também vê-lo simultâneamente como um aprendiz de feiticeiro. Em que medida isto não é uma simples justaposição de termos imcompatíveis, espero deixar claro até o final. Enquanto aprendiz de feiticeiro, o professor vislumbra brechas para uma ação transformadora dentro da Instituição.

Aprendiz de feiticeiro, porque o professor moderno traz o rastro do xamane primitivo:

"Depositário das tradições sagradas, mestre dos rituais de iniciação, o xamane, o feiticeiro, homem-medicina, é o primeiro de todos os mestres-escolas do gênero humano"

Mas esse rastro não oblitera diferenças essenciais. Diferenças que começaram a aparecer desde o momento em que a Humanidade entra na Era da escrita. Com a invenção da escrita e com a descoberta de culturas variadas no tempo e no espaço, segundo Gusdorf, "o encontro educativo situa-se no centro de um espaço intelectual cujos limites se alargam sem fim no espaço e no tempo" A partir daí, o espírito torna-se crítico. O mito é insuficiente. "Constitui-se um saber cuja tarefa é reunir e criticar todos os testemunhos do homem sobre o homem" Sócrates e os sofistas teriam sido os primeiros mestres, que teriam ensinado aos discípulos "o exercício radical da crítica e da inteligência" $O$ mestre da nova era não é o Xamane totalitário, autoridade incontestável. O mestre agora; atingido irremediavelmente

(20) - Utilizamos aqui indistintamente a palavra mestre e a palavra professor, mesmo sabendo que, para Gusdorf, entre outros elas se distiguem radicalmente. Porque gostaríamos de relativisar a distinção. Se é certo que nem todos os professores são mestres; se é certo também que nem todos os mestres são professores, poderiamos dizer, para ficar só no âmbito escolar que em certa medida, todo o professor que não se limite a ser mero repetidor, é mestre, levando em conta que há diferentes graus de maestria. Um professor, que trabalhe seriamente, fazendo sua disciplina em que é especialista, será de certa forma, mestre porque faíscas do seu amor pela que faz acaharão contagiando desigualmente pessoas pela vida à fora, o que já é criar discípulos, mesmo sem atiçar grandes fogueiras.

(21) - Gusdorf, op. cit., p. 271. 
pela dúvida, sabe que a sua não é a única verdade. Aprende o relativo e, com ele, a liberdade do discípulo e a negação de si mesmo como a sua lição mais importante. Símbolo desse mestre cuja última lição é o apagar-se como mestre é Sócrates, falando aos discípulos, no Fédon, de Platão: "Quanto a vós, se me quereis acreditar, não façais grande caso de Sócrates, mas muito mais, da verdade"; e, literalmente, morrendo para seus discípulos, exigindo até o fim o rigor crítico para com suas últimas lições, porque não desejaria ir-se "como abelha, deixando o ferrão" (22)

O mestre tem a consciência da distância radical que o separa do discípulo, o que não lhe permite nem adotar a posse de uma igualdade demagógica, nem cair no autoritarismo. Um mestre sabe que suas lições se assentam sobre um paradoxo: sua palavra "o oculta tanto quanto o exprime" Porque "uma idéia traz a marca daquele que a pensou: o sentido dela estabelece-se pela sua inserção no conjunto de uma paisagem mental indissoluvelmente ligada à totalidade de uma vida"

Mas, mesmo assim um mestre sabe que é modelo, e aceita ser modelo porque isso não quer dizer, necessariamente, que seja autoritário:

"Fará viver aos alunos uma experiência de continuidade com sua vida, embora lhes apresentando modelos, sem temer o que o termo comporte de perfeição e de ruptura fara do quotidiano. A partir do momento em que o modelo realiza esse tipo de ligação, a relação do aluno ao modelo pode ser de submissão sem servilismo nenhum" (24)

Meu mestre sabe que:

"para tomar posse de si mesmo, para reencontrar a força de pensar por si mesmo (o aluno) tem necessidade de um modelo, que o tire das facilidades, das aproximações costumeiras" (25)

(22) - A primeira citação de Sócrates é via Gusdorf pag. 104. A última edição brasileira do Fédon trad. de Jorge Paleika e João Cruz Costa, São Paulo, Abril, 1972. Edição que aliás, traz a frase anterior mais bem traduzida: "Vós, entretanto, se me acreditais, cuidai menos de Sócrates que da verdade" (p. 103)

(23) - Gusdorf, op. cit., p. 305.

(24) - Snyders, op. cit., p. 352.

(25) - Snyders, op. cit., p. 352. 
Meu mestre sabe que:

“a invenção é descoberta a partir do que os outros já estabeleceram. Não é cópia mas reviviscência em mim do que o out o sentiu"

Meu mestre sabe que:

"o modelo pedagógico não é precisamente um dado ( . . ), mas uma fonte, uma estimulação em que cada um se inspira segundo finalidades que persegue, descobrindo que essas finalidades elas mesmas são modificadas, enriquecidas pelo encontro com o modelo". (27)

Meu mestre sabe que:

"o risco pedagógico, o risco de induzir os alunos em erro ou de pesar arbitrariamente sobre sua vontade para dirigí-los em direção ao que nós pensamos ser verdadeiro, esse risco é a definição mesma do enensino -- e se nós devemos sem descanso trabalhar para reduzi-lo não há apesar disso nenhum meio de o suprimir: o ceticismo mole, a indecisão, a recusa de escolher, consistem também em tomadas de posição; conduzir os alunos aí não é menos comprometedor"

Mas, meu mestre sabe, como Gusdorf, que na Universidade:

"Todo mestre traz em si a sombra de um potentado"

e que:

"A vontade de poderio habita também os sábios, sejam eles quais forem" (30)

e que:

"O respeito natural pela hierarquia estabelecida assegura uma fácil eminência ao mestre"

e, ainda que:

"A defesa das posições adquiridas contra eventuais recém-chegados é apenas um aspecto da polemologia universitária"

(26) - Snyders, op. cit., p. 353.

(27) - Snyders, op. cit., p. 353.

(28) - Snyders, op. cit., p. 313.

((29) - Gusdorf, op. cit.., p. 161

(30) - Gusdorf. op. cit., p. 161 .

(31) - Gusdorf, op. cit., p. 162.

(32) - Gusdorf, op. cit., p. 167. 
Mas meu mestre sabe, finalmente, que:

"quem não é capaz de edificar uma obra constrói uma carreira, segundo os caminhos e os meios da arte do arrivismo calculadamente prosseguidos"

Por isso, sua melhor arma contra a "mornura" da Instituição é o seu trabalho.

Por isso, ao invés de fugir à Instituição para manter-se "puro", como quer Blanchot, aí permanece e aí constrói sua obra.

Por isso não permite que a Instituição "dê forma ao seu pensamento" e, ao contrário, "por virtude do muito imaginar", concorre muitas vezes à reforma da Universidade.

Por isso ainda, não recusa os títulos e privilégios que, na Instituição, conquista, usando-os sempre em favor dos interesses do "baixo clero" (34) (35)

E também, por isso, em meio às perseguições, intrigas, bajulações e manobras, nesse espaço minado em que "viver é muito perigoso", o moderno xamane vai passando ileso, corpo fechado "no meio do redemoinho"

Fingindo que não vê as intrigas se armando e os golpes se formando, deixa supor-se candidamente enganado e vai dando a todos uma lição de astúcia e humanidade.

Recusando-se a cair na paranóia geral que faz ver no vizinho um possível traidor, prefere ver no traidor de hoje o colega solidário de amanhã.

Por isso conserva a serenidade para produzir intelectualmente e atuar politicamente, nessa mesma Instituição da qual é o mais alto servidor e o inimigo mais severo. Um perigo; mas que ela acolhe e rejeita indefinidamente, porque dele depende seu prestígio e sua história.

(33) - Gusdorf, op. cit., p. 163.

(34) (35) - Veja-se, por exemplo, para avaliar a pertinência de expressão "clero", as histórias que nos conta Jacques le Goff sobre os Intelectuais na Idade Média (Lisboa, Estudios Cor, 1973). Aí vemos que a Universidade Moderna tem muito ainda das Universidades Medievais, onde também eram comuns as manobras para "destronar" uns dos outros, para conservar ou conquistar privilégios. Veja-se, por exemplo, a história de Abelard, o arquétipo do professor Universitário parisiense, de como conquista o posto de seu mestre Guillaume, pp. 42-43. 
Porque meu mestre sabe:

Que uma Universidade que se preze não se faz sem mestres.

Mas é tempo de recapitular: uma vez "demonstrado" que o mestre existe, uma vez estabelecida a natureza das suas relações com os discípulos, e uma vez descrita a forma como se faz a sua inserção na Universidade, é preciso sondar mais de perto a natureza da sua relação com o seu trabalho, sua obra pessoal de investigação, o alimento constante da sua vida de mestre.

Para começar, sirvo-me novamente de Gusdorf:

"O mestre, antes de surgir como modelo para os outros é aquele que a si próprio se encontrou. Porque a si próprio se conquistou. E aquele que ganhou sua vida e essa é a mais evidente lição de sua forç" (36)

Por isso mesmo não podemos concordar inteiramente com o mesmo autor, quando diz que: (sublinho o que acho discutível)

"Mas em qualquer desses casos, quando a fidelidade da memória está garntida, é preciso reconhecer que ela se liga a qualquer coisa que se situava fora do saber propriamente dito e contava mais do que ela. O saber fornece a ocasião ou pretexto do encontro" (37) "Para além da reflexão sobre as vias e os meios do ensino especializado, abre-se-nos a possibilidade de uma outra investigação que, como uma pedagogia da pedagogia, se exerce sobre a investigação dos processo secretos, graças aos quais, fora de todo o conteúdo particular, se cumpre a edificação de uma personalidade e se processa um destino" (38)

Nessas afirmações, o saber é descartado muito rapidamente. Eu diria até que com certa leviandade. E prefiro considerar que a maestria se faz pelo aprofundamento de um saber determinado, "para o fundo de", e não "para além de" ou "fora do", como quer Gusdorf.

O mestre só é tal pelo crescente domínio que adquire de um saber particular. Negar isso é conceber uma pedagogia desvinculada de um conteúdo, inteiramente formal, portanto.

(36) - Op. cit., p. 115 .

(37) - Op. cit., p. 120

(38) - Op. cit., p.120. 
E preciso, ao contrário, reconhecer com Kourganoff, que:

"Fazer-se compreender é um problema de competência em uma disciplina dada, antes de ser um problema de comunicação no mero sentido psicológico"

No caso dos professores de Letras, a freqüente desvinculação entre a pesquisa pedagógica e a pesquisa teórica sobre a natureza e função da literatura (ou, em muitos casos, a inexistência de uma reflexão séria nos dois campos), tem dado alguns curiosos paradoxos:

- o professor de letras paralisa, mesmo quando ensina que a literatura pode conduzir o leitor a conhecer e a agir.

- o professor de letras, mesmo quando ensina teoricamente que a literatura pode ser fonte de prazer, mata o prazer pelo seu discurso asséptico, que distancia os alunos do texto literário.

- o professor de ietras, mesmo quando ensina que a literatura é criação verbal, abafa a expressão do aluno e contribui ao seu embrutecimento.

- o professor de letras, mesmo quando ensina que a literatura é também ideologia, sacraliza-a, levando o aluno a sacralizá-la, pela relação passiva que este acaba tendo com os textos.

Falta-nos, pois, todo um trabalho para determinar a natureza e a função do objeto de nossas aulas e pesquisas: a literatura. Falta indagar a que serve o seu ensino: como ele serve à Instituição e como e a quê nós queremos que ele sirva dentro dela. Falta vencer a auto-censura e deixar que as questões óbvias se imponham: Para quem ensino literatura? Para que ensino literatura? Que interesses meu trabalho defende? Que interesses pretendo eu que ele defenda? Em que direções aprofundar minhas pesquisas? Em que direções planejar minha atividade didática? Pedagogia supõe transformação: em que sentido meu trabalho fransforma? A mim? aos alunos? Quem são os alunos? qual o seu repertório? qual a sua situação de classe? Qual a consciência que eles têm como aluno? quais as expectativas a que gostariam que eu correspondesse? quais as expectativas que eu gostaria de suscitar neles? etc.

Esse trabalho levaria a reconsiderar em profundidade o lugar que a literatura ocupa na sociedade em geral, no ensino, em particular. E esta simples frase encerra um vasto programa de investigação, que eu não poderia ter a pretensão de desenvolver aqui. Mesmo

(39) - Kourganoff, op. cit., p. 84. 
porque não se trata de começar do zero. Muito desse programa já foi cumprido exatamente por certos professores que, mesmo no Brasil, mergulharam fundo nas questões intrincadas do "texto e ideologia", "literatura e sociedade", "escritor e público", "literatura e formação do homem", entre outras .

Contrariamente a certa maneira idealista de encarar o fenômeno literário (que postula, por exemplo, a ligação necessária entre a obra esteticamente bem realizada e a obra socialmente revolucionária), um trabalho dessa natureza estaria consciente de que as relações entre literatura e sociedade e, mais especificamente, entre literatura e ideologia, são extremamente contraditórias.

Um professor de letras teria, assim, consciência do papel nem sempre revolucionário da literatura, mas saberia também que, apesar disso, "não há sem dúvida, nenhuma grande obra que não seja susceptível de uma reavaliação crítica, que não tenha um papel a desempenhar nessa reavaliação crítica - a partir da qual ela toma uma significação que vai além dos limites da sua classe, ela se torna meio, para as classes dominadas, de chegar à lucidez" (40)

Um professor de letras interpretaria, assim, "as obras dos grandas homens à luz das aspirações populares", procuraria "nas obras dos grandes homens, em que medida respondem às aspirações populares", - "e em que medida também acontece que lhes sejam infiéis"

Como a educação se dirige à personalidade inteira, à afetividade e à inteligência, o professor de letras poderia perguntar-se, entre outras coisas, "como ensinar a literatura de tal modo que as emoções dos poetas se incorporem às emoções vividas dos alunos e lhes comuniquem alguma coisa da sua sutileza, amplitude, brilho" (42)

Um professor de letras levaria em conta o fato de que os escritores podem preencher uma "função educativa nacional", como a chamaria Gramsci. Por isso não se limitaria a exercer uma crítica normativa, nem a trabalhar as grandes obras isoladamente.

A crítica a exercer seria então muito mais "positiva", e a história da literatura que fizesse seria encarada como uma parte, ou um aspecto da história da cultura.

E um professor de literatura seria também um crítico, no sentido de que não teria medo de atirar-se ao estudo das obras do pre-

(40) - Snyders, op. cit., p. 351.

(41) - Snyders, op. cit., p. 351.

(42) - Snyders, op. cit., p. 351. 
sente, das tendências da literatura contemporânea, mesmo que elas não revelem produções ao nível da literatura já consagrada. "Consciente dos contrastes" entre os diversos tipos de cultura, inclusive entre a cultura que ele representa e a representada por seus alunos, tornar-se-ia capaz de viver uma e outra" (43)

Enfim, da relação crítica e aprofundada que esse mestre das letras mantém com a sua disciplina específica, desse grande saber, longamente acumulado e assimilado numa existência feita de reflexão e de leitura, resulta que eu me limito aqui mais a apontá-lo que a descrevê-lo, pois, discípula que sou reconheço a distância radical que me impede o resumo ou a repetição. Apenas gostaria de acentuar que faz parte desse "saber" o reconhecimento dos seus próprios limites. Sendo assim, meu mestre não tem a pretensão de buscar sozinho soluções miraculosas para a ausência de projeto pedagógico na escola moderna. Em vez de sonhar com um gênio salvador, como Gusdorf, prefere considerar que tal projeto não pertence a um homem só, e, enquanto espera que ele seja definido coletivamente, vai fazendo o que pode, explorando a literatura como forma de resistência possível em tudo aquilo que ela tem de contra. Até que dias melhores existam em que possamos definir a favor do quê estaremos colocando o nosso pensamento e a nossa ação, nossas pesquisas e as nossas aulas, norteadas por um "ideal pedagógico" mais coerentemente definido. (44)

Lembraria apenas que a definição de qualquer pedagogia, pelos professores de hoje não pode ignorar um fenômeno que é fator determinante na crise que vivemos: o fenômeno da democratização, da escola em geral, da Universidade, em particular

Em nada avançamos ao rotularmos o processo de democratização que o ensino vive hoje, como sendo um processo de massificação. Recorrer a esse expediente é apenas uma forma de confessar a nossa incapacidade de adaptar a escola às novas condições sociais que ela vive. É querer ridiculamente parar a História, em nome de um "alto padrão" de cultura a defender, de uma Universidade de elite a conservar.

Nesse sentido, tudo está por inventar. Começando pela forma de conceber a aula, a pesquisa, e as relações mestre/discípulo.

Numa universidade em tempo de democratização não cabe mais a aula unicamente conferência, nem o mestre unicamente fala, tal co-

(43) - Siyders, op. cit., p. 350.

(44) - A. Candido, "A cultura do contra" já citado. 
mo o conhecemos tradicionalmente, tal como o definem Blanchot e Barthes:

"A relação do mestre ao discípulos é a relação mesma da palavra, quando nesta o incomensurável se faz medida e a irrelação, relação"

"O que se segue decorre da idéia de que há uma ligação fundamen. tal entre o ensino e a fala" (46)

Mas há falas e falas. A do mestre-xamane não é o discurso que vem do alto da cátedra e do fundo da tradição clássica, mas é parente da fala mansa e bela dos contadores de história. (47)

De qualquer modo, a exigência de atualização da escola implica numa distribuição da fala que desloca a relação mestre/discípulo para uma relação de grupo, em que o mestre se inclui quando baixa do palco, reinaugurando o gesto-símbolo de Celestin Freinet. (48)

Postular isso é, de certa forma, negar o mestre tal como o vimos definindo. Mas, se "o mais alto ensinamento do mestre é apagar o que ensinou e depois apagar-se a si próprio aos olhos dos dicípulos", a negação do mestre é a maior homenagem que lhe presta um discípulo. Mesmo porque, meu mestre sempre soube que:

"O professor universitário é o último tutor, a última segurança diante das solidões da vida em que cada um tem qu' essumir as suas próprias responsabilidades" (49)

Dessa forma, a negação do mestre é, ainda, reflexo das lições apreendidas. Porque um mestre pouco a pouco vai cortando o cordão umbilical àqueles que se obstinam em se perpetuar como discípulos. É a lição mais dura de aprender. É a lição mais triste de ensinar.

(45) - Blanchot, op. cit., p. 5.

(46) - Roland Barthes, Escritores Intelectuais Professo.es e outios ensaios, Lisboa, Presença, p. 25.

(47) - É bom lembrar também que um mestre não é somente fala, como dão a entender os teóricos da maestria. É também um corpo. Uma voz, por exemplo. O esquecimento disso pode ser catastrófico. Para ficar com dois extremos: da voz esganiçada, que, à força de se fazer ouvir nião deix ı escutar, à voz macia, encerrada em si-mesma que, ruma classe de 100 alunos, chega à primeira fila.

(48) - Prof. primário francês que, na década de 20 , em sua pequena escola de província, retirou o estrado destinado ao professor em sua sala, para construir com ele uma mesa, onde instalcu o material de imprensa com que revolucionariamente, alfabetizava seus a'unos. (Ver Elise Freinet, Naissance d'une pedagogie populaire, Paris, Maspero, 1969.

(48) - Gusdo:f, op. cit., p. 66. 
Negar-se como mestre é recusar-se a representar, pelo cultivo de um séquito extemporâneo, a paródia do vivido.

"O mestre é, pois, e necessariamente, um homem só" (50)

(50) - Gusdorf, idem. 